\title{
Features and age dynamics of physical development of schoolgirls aged 14-17 years based on body types
}

\author{
Sergey Blinkov ${ }^{1 *}$, Sergey Levushkin ${ }^{2}$, Mikhail Komlev ${ }^{3}$ \\ ${ }^{1}$ Samara State Agrarian University, 446442, Samara, Russia \\ ${ }^{2}$ Institute of Developmental Physiology of the Russian Academy of Education, 119121, Moscow, \\ Russia \\ ${ }^{3}$ Moscow Polytechnic University, 107023, Moscow, Russia
}

\begin{abstract}
The paper presents the research results on the physical development of high school girls with different body types. It was found that schoolgirls of 14-17 years of astheno-thoracic somatotype were inferior in terms of girth values to their peers who had a muscular-digestive body type. But they have the longest body length. The values of A-T somatotype change most rapidly in most indicators. They have a later development. At the highest rate during this age period the lungs grow at the fastest pace.
\end{abstract}

\section{Introduction}

The problem of preserving and strengthening the health of the younger generation remains one of the priorities in domestic policy of our state. National projects in the field of education and medicine. They are reflected in the Decree of the President of the Russian Federation No. 204 of 07.05.2018, contribute to solving this problem. "On national goals and strategic development objectives of the Russian Federation for the period up to 2024". One of the main components included in the concept of "physical health" and "physical condition" is the indicator of physical development. Generally accepted indicators of physical development, such as body length, body weight, chest circumference, and lung capacity, are used to assess the physical condition of schoolchildren. Many modern children and adolescents have disharmonious physical development and various types of disorders (body weight deficit and obesity, deviations from the musculoskeletal system, low physical activity) [1-3, 7-11].

For the rational organization and scientific justification of schoolchildren physical education, it is necessary to know and take into account the natural development features. According to the periodization, the age of 14-17 years in girls is transitional from adolescence to adultness. Many researchers revealed a slowdown and suspension of the motor qualities and physical performance development and the achievement of the physical development definitive value by schoolgirls $[2,4,6]$.

\section{Materials and Methods}

\footnotetext{
*Corresponding author: blinkovsn@mail.ru
} 
We conducted a research aimed at studying the features and age dynamics of physical development of schoolgirls aged 15-17 years, taking into account the features of their physique.

The research included: 1) Research of anthropometric indicators of physical development (body length and weight, chest circumference) and physiometric value- lung capacity; 2) age dynamics comparative analysis of schoolgirls physical development (14-17 years), of astheno-thoracic and muscular-digestive body types.

All studies conducted in this work were performed with girls in grades 9-11. The study involved 161 schoolgirls of the municipal educational institution Oktyabrskaya secondary school aged 15-17 years. All of them were assigned to the main medical group and had no acute diseases during the experiment.

The research method. The paper uses pedagogical and medico-biological methods that are suitable for studying the physical condition of high school age children: theoretical analysis and generalization of data from scientific and methodological literature; medicobiological methods (anthropometry [5], determination of body types [12].

\section{Results and Discussion}

We evaluated the growth and physical development rates of our subjects during the school year. The tables and charts were created. They reflect changes in the increments of all indicators.

Figure 1 shows age-related changes in the main indicators of 14-17-year-old schoolgirls physical development of astheno-thoracic (A-T) and muscular-digestive (M-D) body types.

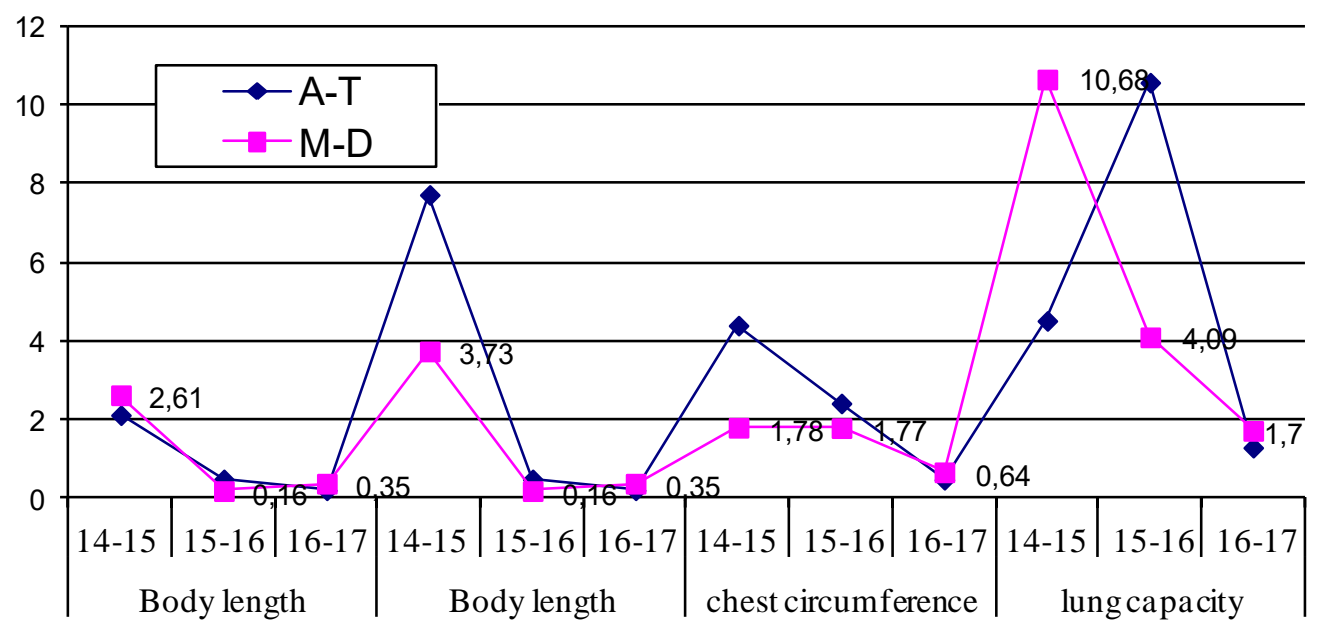

Fig. 1. Increases in physical development of different body types girls aged 14-17 years

Analysis of the age dynamics of girls' physical development shows that the values of A$\mathrm{T}$ somatotype change most rapidly in most indicators. They have a later development. The physical development indicators of high school girls, regardless of their body type, tend to increase slightly with age. The processes of growth and development during this period slow down and for most indicators of physical development reach a definitive value and approach the norm of an adult woman.

The most intense changes in the indicators of LC (from $16.08 \%$ to $35.4 \%$ ) in schoolgirls from 14 to 17 years old, regardless of their body type. The LC (lung capacity) in high school girls, regardless of the body type, changes at the age of 15-16 years and is $10.6 \%$. 
The lowest increase, regardless of the body type of girls, we found in body length (from $0.16 \%$ to $2.61 \%$ ).

The greatest rates of body length and weight, the thickness of skin and fat folds increases in schoolgirls of A-T body type, and chest circumference, hip circumference and wrist perimeter increases the most in schoolgirls of M-D somatotype.

The results of recent research suggest that the most important typological features in physical education are the features of the body [2, 4, 6-7].

In this regard, a study of body types was conducted. We also evaluated the individual properties of each schoolgirl somatics. All of them were divided into 2 typological groups A-T and M-D. Figure 2 shows the somatic structure of girls with different body types.

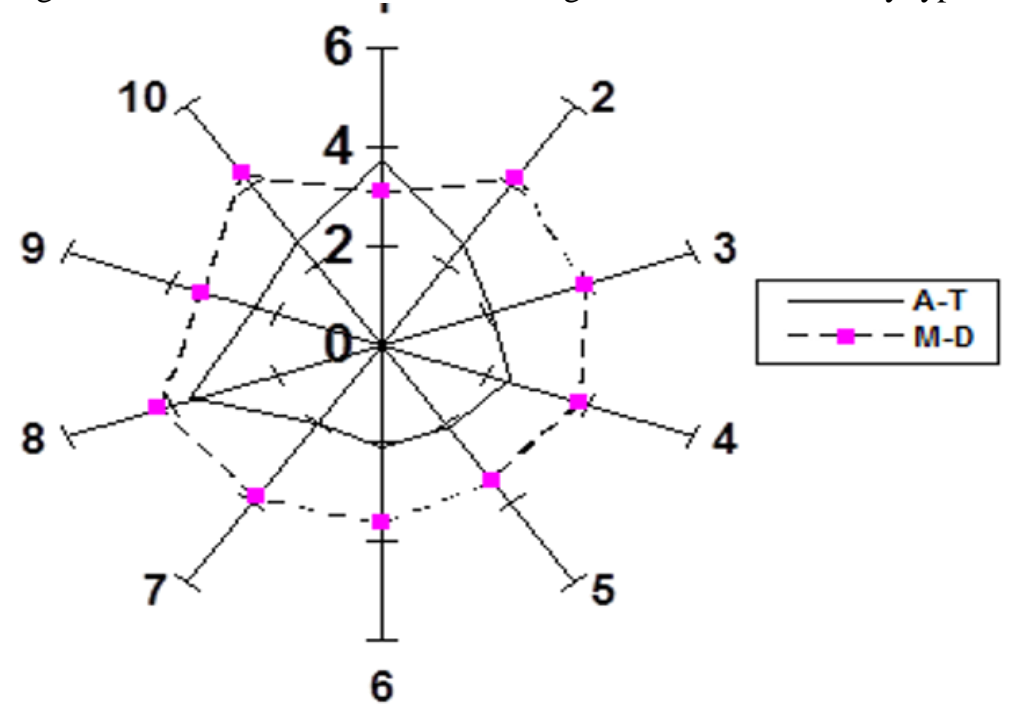

Fig. 2. Star-type graphs for the average values of physical development indicators for girls aged 1516 years of two body types.

Note: the result of each test is expressed in points on a 5-point scale.

1 - body length

2 - body weight

3 - chest circumference

4 - waist circumference

5 - wrist circumference
6 - hip circumference

7 - shoulder circumference

8 - fat fold of the triceps

9 - fat fold under the shoulder blade

10 - fat fold on the abdomen

The diagram of the "star" type presented in figure 2 reflects the structure of somatics in each of the two constitutional types (astheno-thoracic, muscular-digestive) based on the results of ten indicators of physical development. The battery of physical development indicators included body length and weight, chest circumference, waist circumference, wrist circumference, hip circumference, shoulder circumference, skin and fat folds on the triceps, under the shoulder blade, and on the abdomen.

Girls aged 15-16 years of the "muscular-digestive" type (Fig. 2) are characterized by high indicators of physical development, with the exception of body length. It is slightly smaller in size than in girls of the astheno-thoracic somatotype. Representatives of the "astheno-thoracic" body type have the highest indicator in body length. It is clearly seen in figure 2. For all other indicators, girls aged 15-16 years are significantly inferior to representatives of the muscular and digestive body type.

\section{Conclusions}


To improve the physical education process with schoolgirls aged $14-17$, it is necessary to take into account their body types.

Schoolgirls of the muscular-digestive type are characterized by the highest physical development indicators in comparison with girls of the astheno-thoracic somatotype.

The highest rate of physical development increase is among high schoolgirls of asthenic-thoracic somatotype. They have a later development compared to girls of the M-D somatotype.

At the highest rate in this age period, girls of all body types are growing lung capacity. It is comfortable for the aerobic endurance development.

\section{References}

1. A.A. Baranov, V.U. Albitsky, Kazan medical journal, 4(99), 698-705 (2018)

2. S.N. Blinkov, S.P. Levushkin, Scientific notes of The P. F. Lesgaft University, 4(122), 22-29 (2015)

3. S.N. Blinkov, S.P. Levushkin, V.P. Koshikhin, Scientific notes of The P. F. Lesgaft University, 1(119), 42-48 (2015)

4. S.N. Blinkov, S.P. Levushkin, I.M. Smolenskaya, Standards of morphofunctional development of different body types schoolgirls in the Ulyanovsk region (Ulsu, Ulyanovsk, 2007)

5. A.S. Kuznetsov, Z.M. Kuznetsova, Russian Journal of Physical Education and Sport, 14(4), 5-7 (2019). DOI: 10.14526/2070-4798-2019-14-4-5-7

6. S.I. Izaak, Izvestiya vuzov Kyrgyzstan, 9, 153-156 (2016)

7. V.R. Kuchma, Russian pediatric journal, 1(21), 31-37 (2018)

8. S.P. Levushkin, S N. Blinkov, V.I. Boitsov, Standards of schoolchildren physical development in the Samara region: educational and methodological guide (Pero publishing house, Moscow, 2014)

9. R.V. Tambovtseva, New study, 1(22), $92-97$ (2010)

10. R.V. Tambovtseva, New study,1(46), 23-28 (2016)

11. R.V. Tambovtseva, T.V. Panasyuk, New study, 3(44), 5-10 (2015)

12. V.G. Shtefko, A.D. Ostrovsky, Schemes of clinical diagnostics of constitutional types (State med. Izdat., M. - L., 1929) 